\title{
Characterization of Endogenous and Exogenous Mouse Mammary Tumor Virus Proviral DNA with Site-Specific Molecular Clones
}

\author{
BERND GRONER ${ }^{1 *}$ ELENA BUETTI, ${ }^{2}$ HEIDI DIGGELMANN, ${ }^{2}$ AND NANCY E. HYNES ${ }^{1}$
}

Kernforschungszentrum Karlsruhe, Institute for Genetics, D-7500 Karlsruhe 1, Federal Republic of Germany, ${ }^{1}$ and Swiss Institute for Experimental Cancer Research, Epalinges/Lausanne, Switzerland ${ }^{2}$

\begin{abstract}
Restriction fragments of the mouse mammary tumor virus (MMTV) proviral DNA were obtained by molecular cloning procedures. A 4-kilobase fragment delimited by two PstI sites was isolated from unintegrated, linear MMTV DNA and amplified in the pBr322 plasmid vector. EcoRI fragments of proviral DNA, integrated into the genome of a GR mammary tumor cell line, were isolated as $\lambda$ recombinant molecules. Five different recombinant phages which contained the $3^{\prime}$ region of the MMTV proviral DNA and adjacent host DNA sequences were isolated. Heteroduplex analysis and S1 nuclease digestion suggested that there is no extensive sequence homology in the host DNA flanking the different proviral genes. The cloned DNA was fractionated into site-specific restriction fragments which served as molecular probes in the analysis of the endogenous MMTV proviral copies of $\mathrm{C} 3 \mathrm{H}, \mathrm{GR}, \mathrm{BALB} / \mathrm{c}$, and feral mice. This allowed the correlation of MMTV-specific EcoRI fragments obtained from genomic DNA of these strains with the $5^{\prime}$ and $3^{\prime}$ ends of the proviral gene. Restriction fragments of two clones which contained the proviral sequences adjacent to the flanking host DNA as well as 1 to 2 kilobases of host DNA were used as hybridization probes, and the results allow the following conclusions: the proviral DNA of both clones contains nucleotide sequences complementary to the $5^{\prime}$ and $3^{\prime}$ ends of proviral DNA; and the host DNA flanking one clone belongs to the unique class of genomic DNA, whereas the DNA flanking the second clone is reiterated at least 15 times within the mouse genome.
\end{abstract}

Mice which are exogenously infected with mouse mammary tumor virus (MMTV) exhibit early-appearing mammary tumors with a high frequency (1a; R. Michalides and R. Nusse in J. Hilger and $\mathrm{H}$. Sluyser, ed., Mammary Tumors of the Mouse, in press). These mammary tumors contain MMTV proviral DNA in addition to the endogenous proviral copies $(4,10,15,16)$. The acquisition of these exogenous proviral copies in the DNA hints at their role in the process of tumorigenesis. However, it is currently difficult to distinguish the origin of the MMTV RNA and virus particles found in mammary tumors. Are they transcribed from endogenous or from newly acquired MMTV genes? Experiments in which cells have been infected in vitro with MMTV have demonstrated the ability of infecting viral sequences to become integrated into the host genome and subsequently transcribed into viral RNA $(18,24)$. The regulatory effects exerted by glucocorticoid hormones on the transcriptional activity of the MMTV genes in mammary tumor cell lines $(19,26)$ can also be observed in exoge- nously infected cat, mink, and rat cells $(17,20$, 24). These heterologous cells do not contain endogenous MMTV proviral copies. This observation has led to the suggestion that at least some of the regulatory signals responsible for the transcription and hormone induction of viral RNA are located within the proviral DNA (17, 25). The finding, however, that exogenously infected rat hepatoma cells which contain proviral DNA sequences do not necessarily produce viral RNA shows that the integration of viral DNA into the host genome of the infected cells is not sufficient for the transcription of viral RNA (20).

The reason for the different transcriptional activities of MMTV DNA in various rat hepatoma cell clones might be related to the basis of transcriptional differences between endogenous and exogenous proviral genes. By using the Southern DNA filter transfer technique, it has been possible to distinguish the location of exogenous MMTV proviruses present in mammary tumor DNA from the location of those endogenous to the mouse $(3,4,6)$. These differ- 
ences in genomic locations could, in turn, be important in determining the transcriptional properties of individual proviral genes. The elucidation of the role that proviral as well as adjacent host DNA sequences play in the regulation of viral gene expression is important. To analyze viral and adjacent host DNA sequences, we have constructed recombinant $\lambda$ phage clones (12) containing inserts of DNA derived from a GR mammary tumor cell line (19). This cell line has 50 to 60 copies of MMTV proviruses integrated into its genome. The recombinant phages selected contain nucleotide sequences of six different proviral copies and their adjacent host DNA. We have also constructed a recombinant pBr322 plasmid carrying an internal 4-kilobase (kb) DNA fragment derived from unintegrated MMTV DNA. We have used restriction enzyme fragments obtained from defined locations within the recombinant DNA as probes in Southern DNA filter transfer experiments to study the DNA from three different inbred strains (GR, BALB/c, and $\mathrm{C} 3 \mathrm{H} / \mathrm{HeJ}$ ) and one feral mouse. The results allow us to draw some conclusions concerning the terminal structure of the cloned proviral copies and the nature of the host DNA sequences adjacent to two of the proviral copies in the mammary tumor cell line with respect to their reiteration in the mouse genome.

\section{MATERIALS AND METHODS}

Preparation of $\lambda$-MMTV recombinant phage DNA. High-molecular-weight DNA was prepared from GR cells, which originated from a GR mammary tumor, as previously described (6). DNA (200 $\mu \mathrm{g})$ was digested to completion with EcoRI restriction enzyme (Boehringer Mannheim Corp.) and separated by preparative agarose gel electrophoresis. The 4- to 8-kb region of the gel was cut out, and the agarose strip was crushed in $20 \mathrm{ml}$ of $7 \mathrm{M}$ urea, $150 \mathrm{mM} \mathrm{NaCl}, 10 \mathrm{mM}$ Tris-hydrochloride, $\mathrm{pH} 7.5$, and $1 \mathrm{mM}$ EDTA, using a Dounce homogenizer. After shaking for $12 \mathrm{~h}$ at $37^{\circ} \mathrm{C}$, the agarose was pelleted by centrifugation for $1 \mathrm{~h}$ at 20,000 rpm in a Beckman SW27 rotor, and the supernatant was diluted twofold with TNE $(0.1 \mathrm{M} \mathrm{NaCl}, 10$ $\mathrm{mM}$ Tris-hydrochloride, $\mathrm{pH} 7.5$, and $5 \mathrm{mM}$ EDTA). The DNA was recovered by passage through DEAEcellulose, elution with $1 \mathrm{M} \mathrm{NaCl}-10 \mathrm{mM}$ Tris-hydrochloride (pH 7.5)-1 mM EDTA, and ethanol precipitation. $\lambda g t$ WES- $\lambda B$ DNA was prepared as described in the owner's manual accompanying the $\lambda g t$ WES- $\lambda B$ cloning kit (13). $\lambda B$ was removed after digestion with EcoRI and gradient centrifugation as described by Maniatis et al. (14). Then $0.3 \mu \mathrm{g}$ of purified $\lambda$ arms was ligated with $0.05 \mu \mathrm{g}$ of EcoRI-digested GR cell line DNA of 4 to $8 \mathrm{~kb}$ in a $50-\mu \mathrm{l}$ reaction containing $66 \mathrm{mM}$ Tris-hydrochloride, $\mathrm{pH} 7.6,6 \mathrm{mM} \mathrm{MgCl}_{2}, 10 \mathrm{mM}$ dithiothreitol, $1 \mathrm{mM}$ ATP, and $1 \mathrm{U}$ of T4 DNA ligase (BRL, Inc.) for $12 \mathrm{~h}$ at $2^{\circ} \mathrm{C}$. The ligated DNA was packaged in vitro into $\lambda$ phage heads as described by
Hohn and Murray (8). The phages were titrated on bacterial strain BHB 2600 , and the entire phage population was amplified as described by Maniatis et al. (14). The amplified phages were plated at a density of $10^{4}$ plaques per petri dish, and the DNA was transferred on a nitrocellulose filter. The filters were hybridized to ${ }^{32}$ P-MMTV complementary DNA (cDNA) (1). Positive areas in the plaque lawn were identified, and the phages from these areas were eluted. Single plaques of $\lambda$-MMTV recombinant phages were obtained after two further rounds of phage plating and filter hybridization at a phage density of $10^{3}$ and $10^{2}$ per plate.

Preparation of pBr322-MMTV recombinant plasmid DNA. Linear, unintegrated MMTV DNA was isolated from the cytoplasm of HTC-M1 cells, a rat hepatoma cell line infected with MMTV (GR) (18), using a procedure described previously (6). Cytoplasmic DNA extracted from 50 10-cm tissue culture dishes was digested with PstI and electrophoresed on a $1 \%$ agarose horizontal slab gel $(35 \mathrm{~V}, 20 \mathrm{~h})$. A gel strip containing a portion of the digested DNA and molecular weight markers was removed, stained with ethidium bromide, and transferred to a nitrocellulose filter (23). The filter was then hybridized to ${ }^{32} \mathrm{P}$-labeled MMTV cDNA and exposed to an X-ray film. The autoradiographic pattern obtained (Fig. 1, lane 1) was identical to the one previously described (6). The autoradiograph was aligned with the preparative gel, and a slice containing DNA of $4 \mathrm{~kb}$ in size was cut out and the DNA was recovered as described above. Twofifths of the DNA was used for a T4 ligase-mediated ligation reaction $\left(6\right.$ days, $4^{\circ} \mathrm{C}$ ) with $100 \mathrm{ng}$ of the plasmid vector $\mathrm{pBr} 322$ (2). The vector DNA had been treated with bacterial alkaline phosphatase at $65^{\circ} \mathrm{C}$ for $1 \mathrm{~h}$ to reduce recircularization. The ligated mixture $(10 \mu$ l) was diluted 20 -fold and used for transfecting $\mathrm{CaCl}_{2}$-treated Escherichia coli strain HB101. Approximately $10^{3}$ tetracycline-resistant colonies were obtained. These were transferred to agar plates covered with a sterile membrane filter (Millipore Corp.). The ligated vector alone yielded about 30 colonies. The colonies were screened by hybridization with ${ }^{32} \mathrm{P}$-labeled MMTV cDNA (7). Two positive colonies were isolated and shown to contain the 4-kb PstI A fragment of MMTV DNA, in different orientations with respect to the vector. One clone was grown preparatively, and the recombinant plasmid was purified by centrifugation in ethidium bromide-containing $\mathrm{CsCl}$ density gradients. Figure 1 shows the ethidium bromide-stained pattern obtained after digestion of the recombinant $\mathrm{pBr} 322-\mathrm{MMTV}$ plasmid with PstI (lane 2) and PstI and EcoRI (lane 5). These two lanes were transferred by the Southern blotting method to nitrocellulose sheets and hybridized to ${ }^{32} \mathrm{P}-\mathrm{MMTV}$ cDNA (lanes 3 and 4). After digestion with EcoRI, the 4-kb DNA band was found to contain MMTV-specific sequences (lane 3). After the digestion with $E c o R I$ and PstI, the 3.1- and 0.9-kb bands were found to contain sequences complementary to MMTV (lane 4).

Gel electrophoresis of DNA and filter transfer analysis. Restriction enzyme-digested DNA was separated electrophoretically on $0.8 \%$ agarose gels as described previously (6). The transfer of DNA to nitro- 


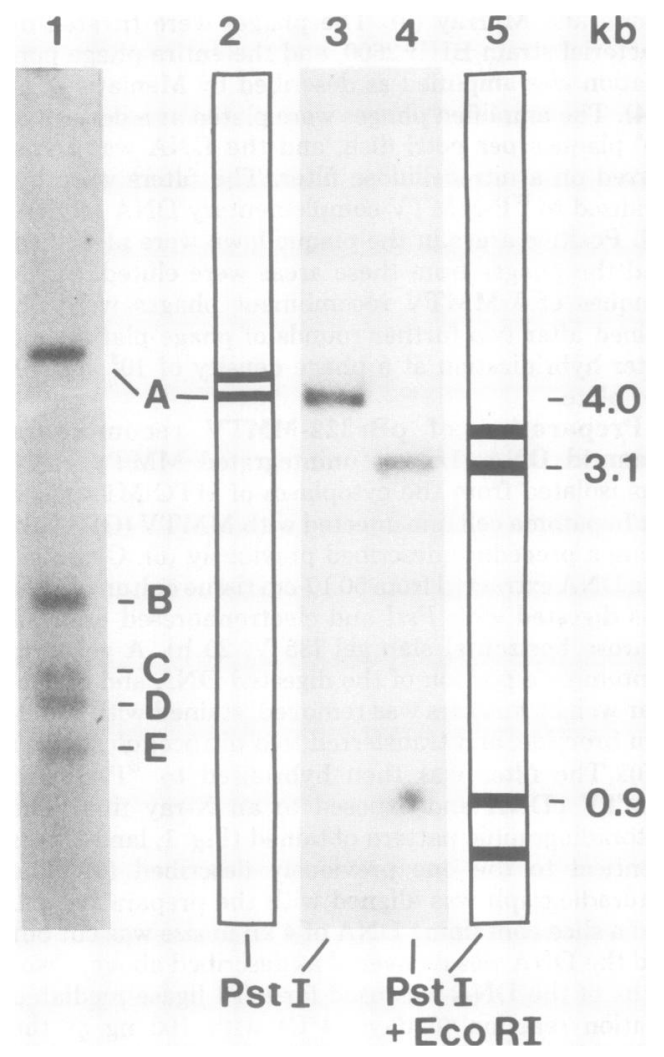

Fig. 1. Cloning of MMTV DNA 4-kb PstI frag. ment. Lane 1: Southern blot analysis of PstI-digested cytoplasmic DNA from HTC-M1 cells. The hybridizations shown in lanes 1,3 , and 4 were carried out with $^{32}$ P-labeled MMTV cDNA. Lanes 2 and 5: Schematic drawing of an ethidium bromide-stained $1 \%$ agarose gel containing recombinant $p B r 322$ plasmid DNA digested with PstI (2) and PstI plus EcoRI (5). Lanes 3 and 4: Southern blot analysis of slots 2 and 5. The nonhybridizing DNA bands in lanes 2 and 5 represent plasmid pBr322 DNA. The PstI fragments generated by digestion of cytoplasmic MMTV DNA are labeled $A$ through $E$. Fragment $A$ was inserted into the plasmid vector. The 3.1-kb PstI/EcoRI fragment shown in lanes 4 and 5 was preparatively isolated and used as a hybridization probe in the experiment shown in Fig. 6A.

cellulose filters was carried out by the blotting procedure of Southern (23), and hybridization of nitrocellulose filters was performed as previously described (6). ${ }^{32} \mathrm{P}$-MMTV cDNA or nick-translated restriction enzyme fragments, both of a specific activity of approximately $5 \times 10^{7} \mathrm{cpm} / \mu \mathrm{g}$, were used as hybridization probes.

Restriction enzyme mapping of cloned DNAs. Recombinant $\lambda$-MMTV DNA of clones 1 through 6 was digested to completion with EcoRI. The DNA was subsequently digested with DNA $(0.1 \mathrm{U} / \mu \mathrm{g})$ of either BamHI or PstI for 6, 20, and $60 \mathrm{~min}$. The DNA of the three BamHI digests and PstI digests was then pooled, and $50 \mathrm{ng}$ of each was electrophoretically separated on an agarose gel. The DNA was transferred to a nitrocellulose filter and hybridized to ${ }^{32} \mathrm{P}$ nicktranslated fragment $E_{1}-B_{1}$ of clone 3 DNA (schematically described in Fig. 4). The resulting fragment pattern was used to relatively orient the restriction enzyme sites for EcoRI, BamHI, and PstI. This technique has recently been described (21).

Heteroduplex formation and S1 nuclease analysis. The EcoRI fragments of the $\lambda$-MMTV recombinant phages containing DNA complementary to MMTV were isolated by preparative gel electrophoresis after removal of the $\lambda$ arms by gradient centrifugation (14). Five nanograms of purified fragments was mixed in pairs as described in Fig. 4. The mixture was heated to $68^{\circ} \mathrm{C}$ for $10 \mathrm{~min}$ in a $50-\mu l$ reaction containing $70 \%$ formamide, $0.3 \mathrm{M} \mathrm{NaCl}, 10 \mathrm{mM}$ Trishydrochloride ( $\mathrm{pH} \mathrm{8.5)}$, and $1 \mathrm{mM}$ EDTA. The DNA was allowed to reanneal for $1 \mathrm{~h}$ at $37^{\circ} \mathrm{C}$ and was subsequently diluted into $500 \mu \mathrm{l}$ of $\mathrm{S} 1$ nuclease assay buffer ( $0.3 \mathrm{M} \mathrm{NaCl}, 0.03 \mathrm{M}$ sodium acetate, $\mathrm{pH} 4.5,3$ $\mathrm{mM} \mathrm{ZnSO}_{4}$, and $10 \mu \mathrm{g}$ of denatured calf thymus DNA per $\mathrm{ml}$ ). One unit of $\mathrm{S} 1$ nuclease (a gift from $U$. Schibler) was added, and the DNA was digested for 1 $h$ at $37^{\circ} \mathrm{C}$. The DNA was precipitated with ethanol in the presence of $10 \mu \mathrm{g}$ of carrier DNA and analyzed by gel electrophoresis, filter transfer, and hybridization to ${ }^{32}$ P-MMTV cDNA.

\section{RESULTS}

Molecular cloning of MMTV proviral DNA. GR cells, an MMTV-producing cell line derived from a mammary tumor taken from a GR mouse, contain 50 to 60 copies of MMTV proviral DNA per diploid genome. This was determined by gene titration using a representative MMTV cDNA probe (N. Hynes, unpublished data). The GR mouse and its mammary tumor tissue contain approximately 10 copies of proviral DNA per diploid genome (6); i.e., the mammary tumor cell line has acquired $\mathbf{4 0}$ to $\mathbf{5 0}$ MMTV copies. The mechanism of acquisition of new proviral DNA is unclear but may function via reinfection of cells by viral particles or direct intracellular reverse transcription of viral RNA produced by the same cell. We identified the EcoRI fragments obtained from GR cell line DNA which contain MMTV sequences by the Southern DNA filter transfer technique (Fig. 2). A great number of bands reflecting the multiple proviral copies can be observed in the 4- to 8-kb region of the gel. Since EcoRI cut the DNA of the GR exogenous viral variant once, each band represents a restriction fragment delimited on one side by the provirus internal EcoRI recognition site and on the other by the nearest $E c o R I$ site occurring in the adjacent host DNA. To isolate recombinant DNA molecules containing MMTV-specific sequences, GR cell line DNA was digested to completion with EcoRI, and 


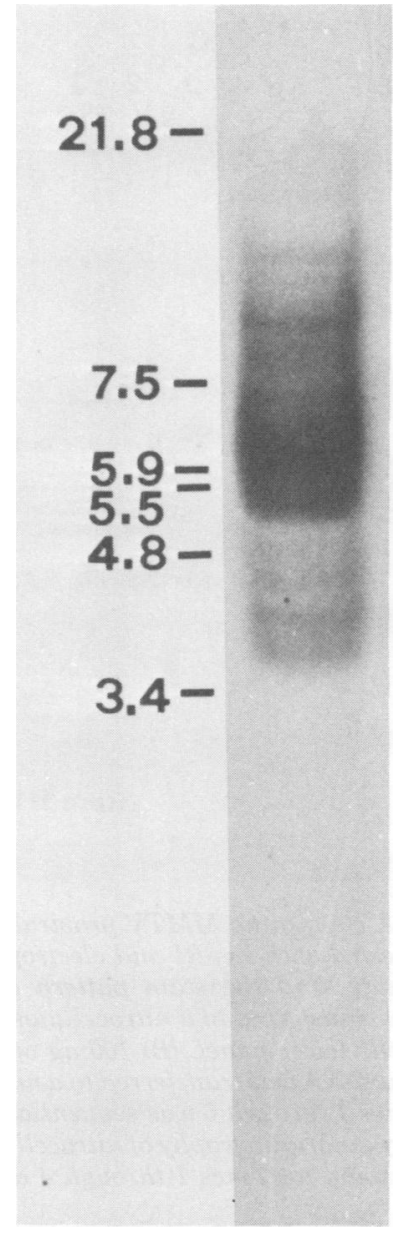

Fig. 2. Analysis of MMTV proviral sequences in the DNA of the GR cell line. Five micrograms of DNA isolated from the GR cell line was digested with EcoRI. The sample was electrophoresed in a $0.8 \%$ agarose gel, transferred to a nitrocellulose filter, and annealed with ${ }^{32}$ P-labeled MMTV CDNA as described in the text. The markers indicate the position of the fragments of EcoRI-cut lambda phage DNA (in kilobases) detected by staining with ethidium bromide.

DNA fragments electrophoresing between 4 and $8 \mathrm{~kb}$ were isolated by preparative gel electrophoresis. These $E c o R I$ fragments were inserted into the arms of the $\lambda \mathrm{gt}$ WES vector. Then $0.3 \mu \mathrm{g}$ of $\lambda$ arms was ligated with $0.05 \mu \mathrm{g}$ of $4-$ to 8 -kb EcoRI fragments of GR cell line DNA, and the recombinant DNA was packaged into phage particles in vitro. The yield of recombinant phage was titered, and $5 \times 10^{4}$ phage plaques per 0.35 $\mu g$ of DNA were obtained. When no GR DNA was added to the ligation of the purified $\lambda$ arms, $2.1 \times 10^{3}$ phage plaques were observed per 0.3 $\mu \mathrm{g}$ of $\lambda$ arms. The addition of $0.05 \mu \mathrm{g}$ of purified $\lambda B$ yielded $2.7 \times 10^{5}$ plaques per $0.35 \mu \mathrm{g}$. The background contributed by the packaging mix alone was zero. Thus, approximately $95 \%$ of the plaques obtained contained recombinant phage DNA.

After amplification of the obtained recombinants, $\lambda$ phages containing MMTV-specific sequences were selected by screening $2 \times 10^{5}$ plaques, using the filter lift procedure, followed by hybridization with ${ }^{32} \mathrm{P}$-MMTV cDNA. Eleven single plaques were purified, and their DNA was analyzed by restriction enzyme digestion, gel electrophoresis, and hybridization of Southern blots to MMTV cDNA. The UV fluorescence patterns after ethidium bromide staining of EcoRI-digested DNA from six individual clones is shown schematically in Fig. 3A (upper panel). Three of the eleven clones obtained yielded patterns identical to that of clone 1 after digestion with EcoRI, BamHI, and PstI. 'Three clones were identical to clone 5 , and two clones were identical to clone 2. We suspect that the identical clones are siblings which arose during the amplification of the total $\lambda$ phage population. The remaining six different clones are shown in Fig. $3 A$. Of these, clones 1,4 , and 5 contained two $E c o R I$ fragments in addition to the $\lambda$ arms. In each case, the sum of the two fragments exceeded the size of the GR DNA fragment selected for ligation with the $\lambda$ arms. Therefore, it is likely that these clones arose by ligation of GR DNA EcoRI fragments before their insertion into $\lambda$ arms. Southern hybridization analysis demonstrated that only one of the EcoRI fragments of clones 1,4 , and 5 and the single inserts of clones 2, 3, and 6 hybridized with MMTV cDNA (Fig. 3A, lower panel).

Double digestion of the $\lambda$ clone DNAs with EcoRI and BamHI or EcoRI and PstI and hybridization of the resulting restriction fragments with MMTV cDNA after Southern blotting was carried out (Fig. 3B, C). Figure 4 shows a partial restriction enzyme map for each of the six clones. The maps were obtained as follows. The results from the original Southern blotting analysis showed that five of the clones had the same PstI and BamHI fragments as have been mapped on the unintegrated viral DNA (22). To order these fragments and to show that the sites are the same, we isolated the fragment $E_{1}-B_{1}$ after an EcoRI/BamHI double digest of clone 3 DNA. The DNA from clones 1 through 6 was digested to completion with $E c o R I$ and subsequently partially digested with PstI or BamHI. The partial digests were electrophoresed and a Southern blotting analysis was performed, using nicktranslated fragment $E_{1}-B_{1}$ as a probe. This tech- 


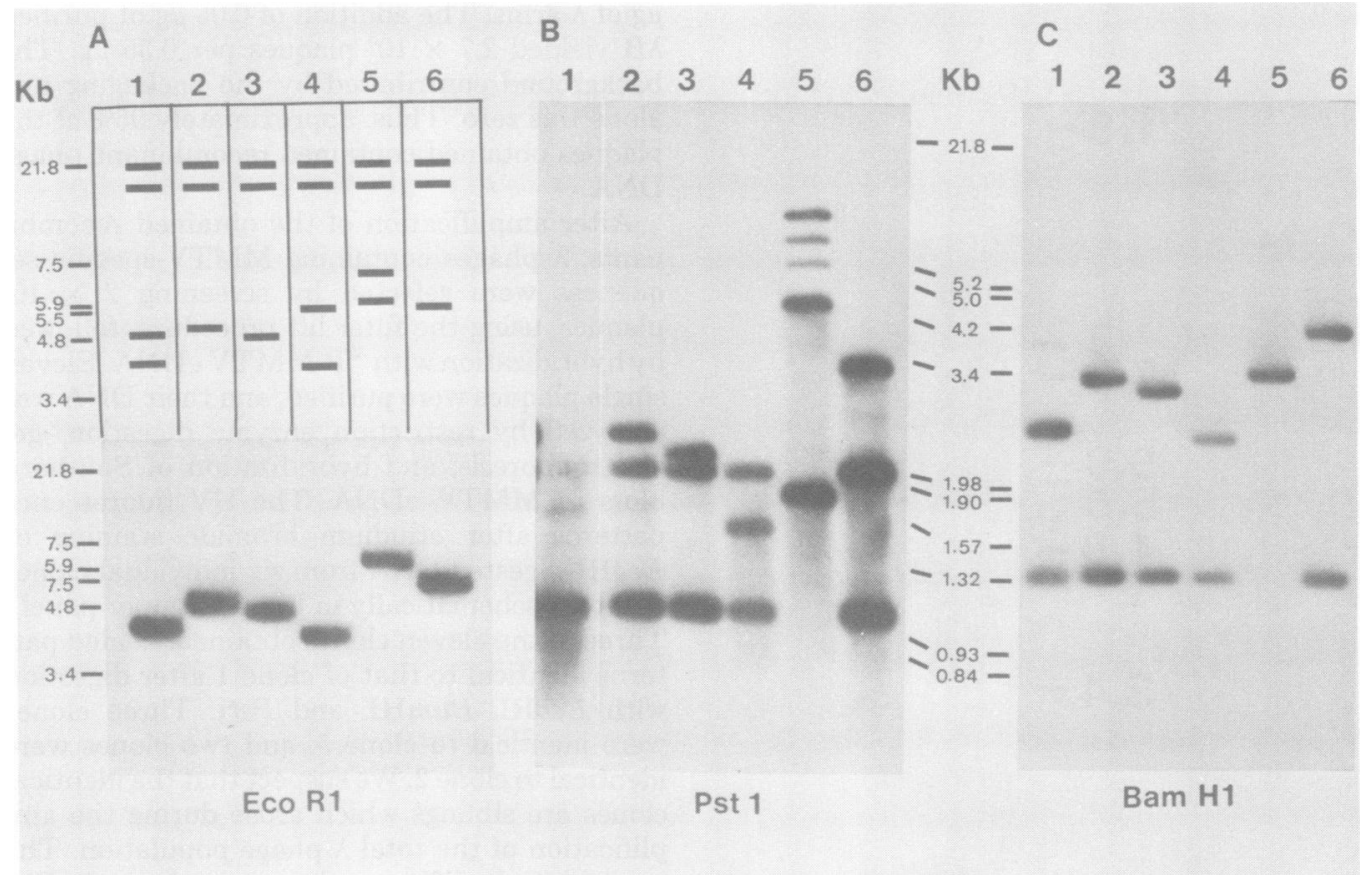

Fig. 3. Restriction enzyme analysis of recombinant $\lambda$ phage DNA containing MMTV proviral sequences. (A) $100 \mathrm{ng}$ of DNA from six individually isolated $\lambda$ phages was digested with EcoRI and electrophoresed in a $0.8 \%$ agarose gel. The DNA was stained with ethidium bromide, and the stain pattern obtained is schematically shown in the upper panel. The DNA was subsequently transferred to a nitrocellulose filter and hybridized to ${ }^{32}$ P.MMTV cDNA. The autoradiogram is shown in the lower panel. (B) $100 \mathrm{ng}$ of DNA from clones 1 through 6 was sequentially digested with EcoRI and PstI. The DNA was transferred to a nitrocellulose filter and hybridized to MMTV cDNA. (C) $100 \mathrm{ng}$ of DNA from clones 1 through 6 was sequentially digested with EcoRI and BamHI. The MMTV-specific DNA was visualized by autoradiography of nitrocellulose filters hybridized to MMTV cDNA. The smallest fragment of $0.55 \mathrm{~kb}$ common to clones 1 through 4 and 6 is not shown.

nique has recently been described (21) and is similar to an end-labeling analysis except that a small fragment of DNA, which we assumed was common to the end of five of the clones, was used as a probe. The resulting hybridization patterns (data not shown) allowed us to order the various restriction enzyme sites relative to this fragment. Clone 5 did not hybridize to fragment $E_{1}-B_{1}$. The hybridization of double digests (EcoRI and BamHI or EcoRI and PstI) of clone 5 DNA with the defined fragments $B_{1}-B_{2}$ and $B_{2}-E_{c 3}$ of clone 3 allowed the construction of a tentative restriction enzyme map of clone 5 DNA (Fig. 4).

Five of the six clones analyzed contained five restriction enzyme sites for EcoRI, BamHI, and PstI which are characteristic for the right-hand side of the exogenous MMTV-GR variant (22). The distance from the PstI site $\mathrm{P}_{2}$ to the $E$ coRI site in the flanking host DNA was found to be different in all the clones examined. This has previously been regarded as an indication for the different genomic locations of the proviral genes.
To further characterize the flanking host DNA and to map the DNA region common to the different clones, heteroduplexes of cloned DNA were analyzed. Isolated MMTV-specific EcoRI fragments from clones $2,3,4$, and 6 were mixed in pairs, denatured, and allowed to reanneal. They were then treated with nuclease S1, electrophoresed, and hybridized with ${ }^{32} \mathrm{P}-\mathrm{MMTV}$ cDNA after filter transfer. In addition to the input restriction fragments (shown individually in the lower panel of Fig. 3A), a third band of 4 $\mathrm{kb}$ is visible in all four lanes of Fig. 5 . This band was not observed when only a single species of cloned DNA was subjected to the denaturation, renaturation, and $\mathrm{S} 1$ nuclease procedure. However, some fainter bands migrating faster were also observed in the control experiment. These bands were probably due to single-stranded breaks in the EcoRI fragments present before denaturation. The band of $4 \mathrm{~kb}$ probably represents the common proviral DNA sequence present in the various clones and was derived from the formation of heteroduplex molecules. This 


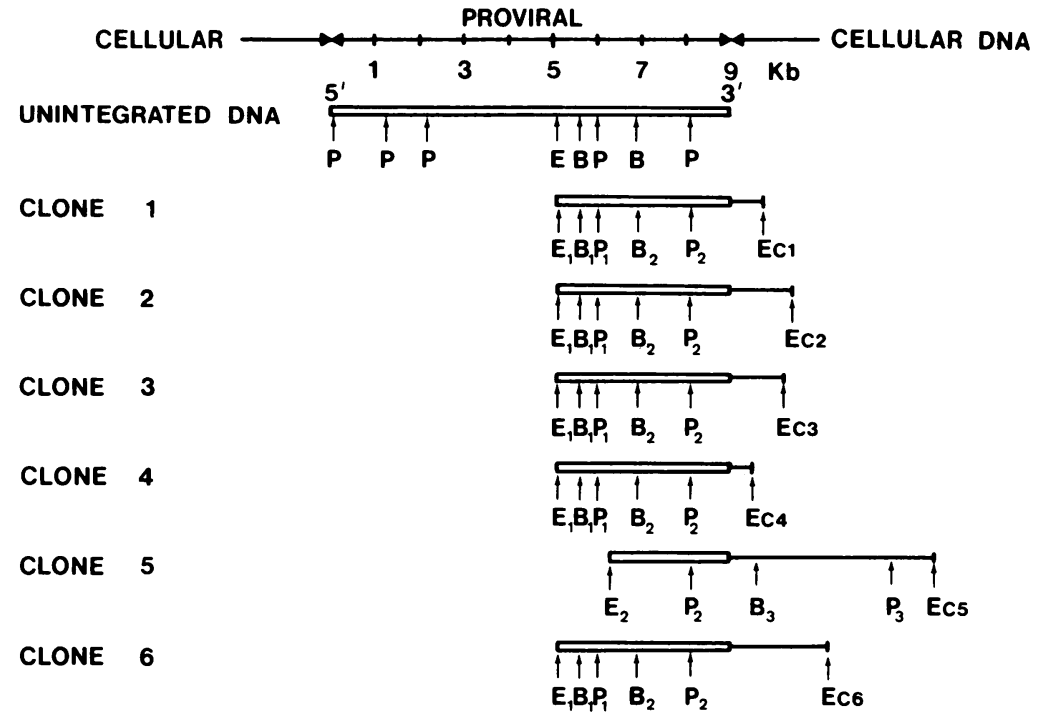

Fig. 4. Scheme of the restriction patterns of MMTV proviral DNA and adjacent host DNA of clones 1 through 6. The restriction sites for the enzymes EcoRI (E), BamHI (B), and PstI (P) are shown. The sites were oriented with respect to each other as described in Materials and Methods. A comparison to unintegrated linear MMTV DNA is shown. The data were taken from Shank et al. (22). Clones 3 and 6 were further fractionated after digestion with $B$ amHI. Fragments $B_{1}-B_{2}$ of $1.3 \mathrm{~kb}, B_{2}-E_{\mathrm{C}_{3}}$ of $3.3 \mathrm{~kb}$, and $B_{2}-E_{\mathrm{C} 6}$ of $4.3 \mathrm{~kb}$ were used as hybridization probes in the experiments described in Fig. 6 and 7. The suffixes denote the first and second BamHI and PstI sites to the right of the EcoRI site. $E_{\mathrm{c}}$ refers to the EcoRI site in the host DNA to the right of the proviral sequence.

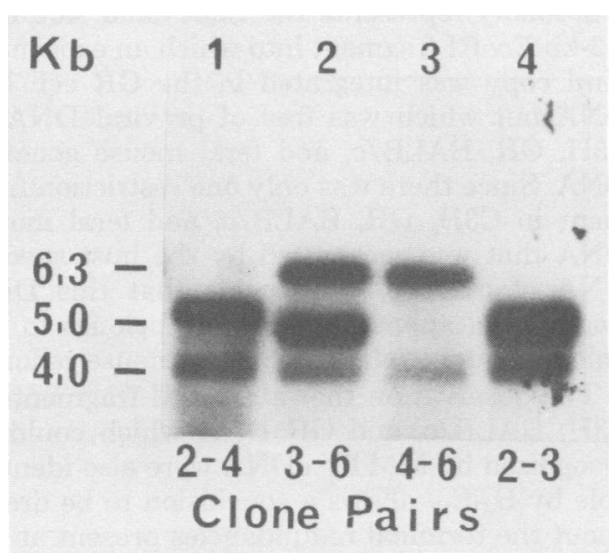

Fig. 5. Heteroduplex analysis of MMTV proviral and adjacent host DNA sequences. The MMTV-specific EcoRI fragments shown in Fig. 3 were preparatively isolated. Five-microgram samples of clones 2 and 4 (lane 1), clones 3 and 6 (lane 2), clones 4 and 6 (lane 3), and clones 2 and 3 (lane 4) were mixed, denatured, and allowed to renature as described in Materials and Methods. The DNA was subsequently treated with S1 nuclease and electrophoresed on an agarose gel. The DNA was transferred to a nitrocellulose filter and hybridized to ${ }^{32} P-M M T V$ cDNA.

experiment suggests that the base sequence of the host DNA adjacent to the different proviral genes does not exhibit extensive base sequence homology and is $\mathrm{S} 1$ nuclease sensitive upon heteroduplex formation.

Hybridization of mouse genomic DNA with defined MMTV DNA-containing fragments. The MMTV proviral DNA endogenous to various inbred strains of mice has previously been characterized. The analyses were carried out by digestion of liver DNA with restriction enzymes, Southern transfer, and identification of restriction fragments containing proviral sequences with MMTV cDNA. Each strain yielded a characteristic pattern of bands $(5,6$, 10). The molecular amplification of proviral sequences has enabled us to use specific fragments of proviral DNA as probes to further characterize the endogenous proviruses of various mouse strains.

The recombinant plasmid pBr322 carrying the internal 4-kb PstI fragment of the exogenous MMTV-GR unintegrated DNA described in Materials and Methods was digested with PstI and EcoRI. A fragment containing $3.1 \mathrm{~kb}$ of DNA from the left of the internal EcoRI site found in this MMTV proviral variant (22) was preparatively isolated and used as a probe to identify MMTV-containing EcoRI fragments of C3H, GR, and BALB/c liver DNA. If all endogenous proviral MMTV copies are cut by EcoRI at the same position, one expects this 3.1-kb PstI/EcoRI fragment to recognize only the left- 
hand proviral fragments. The results of this hybridization are shown in Fig. 6A. A probe complementary to the right-hand side of MMTV proviral DNA was cleaved from a BamHI digestion of the MMTV-containing EcoRI fragment of clone 3 DNA. The fragment $B_{1}-B_{2}, 1.3 \mathrm{~kb}$ in length, was isolated, nick translated, and hybridized to a filter on which electrophoretically separated $E$ coRI-digested DNA isolated from C3H, GR, and BALB/c liver had been bound (Fig. 6C). A comparison with the EcoRI fragments which hybridized with MMTV cDNA (Fig. 6B) reveals that the two probes hybridized with complementary sets of MMTV-specific EcoRI restriction fragments. The molecular weights of the endogenous MMTV-containing EcoRI fragments and the results of the hybridizations with the two specific probes are listed in Table 1.

The only fragment which hybridized with MMTV cDNA but could not be assigned to either a left- or a right-hand EcoRI band of proviral DNA was the 14.5 -kb fragment generated by BALB/c DNA. This fragment has previously been identified by Cohen et al. (3) to contain a subgenomic unit of proviral DNA. Although this unit hybridized with MMTV cDNA and with a probe specific for the $3^{\prime}$ end of the viral RNA, it is not recognized by the specific left-hand or right-hand probes which we have used for these experiments.

Cohen et al. (3) have mapped the two intact MMTV proviruses endogenous to BALB/c mice. The fragments which we have identified as left and right agree with their map. According to their data the 7.5- and 6.1-kb fragments form one provirus, whereas the $7.1-$ and $9.6-\mathrm{kb}$ fragments form the other.

Hybridization of mouse genomic DNA with two cloned DNA fragments which include proviral as well as neighboring host sequences. Mammary tumors arising in mice after MMTV infection contain increased numbers of proviral gene copies. Analysis by the DNA filter transfer technique has revealed that newly acquired MMTV DNA copies are present in a number of different genomic locations $(4,6)$. The differences in locations have been deduced from the EcoRI sites in host DNA adjacent to the proviral genes. The availability of molecular clones containing the junctions of proviral and host sequences from the GR cell line enabled us to further characterize the host DNA adjacent to the proviral clones 3 and 6 . For this purpose, we isolated the DNA restriction fragments $B_{2}$ $F_{C 3}$ of clone 3 and $B_{2}-E_{C 6}$ of clone 6 by preparative gel electrophoresis (Fig. 4). Fragment $B_{2^{-}}$ $\mathrm{E}_{\mathrm{C} 3}$ was about $3.2 \mathrm{~kb}$ in length and contained approximately $2.1 \mathrm{~kb}$ of proviral DNA from the right-hand end of the provirus and $1.1 \mathrm{~kb}$ of DNA from the adjacent host genome. Fragment $B_{2}-E_{C_{6}}$ of about $4.2 \mathrm{~kb}$ was composed of the same $2.1 \mathrm{~kb}$ of proviral DNA and $1.1 \mathrm{~kb}$ of DNA of host origin. Fragments $B_{2}-E_{C 3}$ and $B_{2}-E_{C 6}$ were nick translated and used as hybridization probes after the filter transfer of EcoRI-digested DNA isolated from $\mathrm{C} 3 \mathrm{H}, \mathrm{GR}, \mathrm{BALB} / \mathrm{c}$, and feral mouse livers as well as GR cell line DNA. Figure $7 \mathrm{~B}$ shows the pattern obtained when $\mathrm{B}_{2}-\mathrm{E}_{\mathrm{C} 6}$ was used as a radioactive probe. $\mathrm{C} 3 \mathrm{H}, \mathrm{GR}$, and $\mathrm{BALB} / \mathrm{c}$ DNA yielded a pattern very similar to the one obtained when MMTV $\mathrm{cDNA}$ was used as a probe (Fig. $7 \mathrm{C}$ ). The small fragments of approximately $1 \mathrm{~kb}$ visible in $\mathrm{C} 3 \mathrm{H}, \mathrm{GR}$, and GR cell line DNA are also seen with an MMTV cDNA probe (see Fig. 6 or Fig. 3 of reference 6), but they are not included in the schematic diagram. However, one additional band indicated by the markers in Fig. 7B can be observed. This band, of about $8.3 \mathrm{~kb}$, was shared by $\mathrm{C} 3 \mathrm{H}$, $B A L B / c$, and feral mouse DNA. If this band was also present in GR liver DNA, it was difficult to see since there were two endogenous fragments in this region of the gel. This restriction fragment probably contains a site in the GR cell line DNA into which MMTV viral DNA has been integrated. The approximately $2 \mathrm{~kb}$ of host DNA attached to the end of the proviral DNA of clone 6 probably represents the right-hand side of a 8.3-kb EcoRI fragment into which an exogenous viral copy was integrated in the GR cell line DNA but which was free of proviral DNA in C3H, GR, BALB/c, and feral mouse genomic DNA. Since there was only one restriction fragment in $\mathrm{C} 3 \mathrm{H}, \mathrm{GR}, \mathrm{BALB} / \mathrm{c}$, and feral mouse DNA that was recognized by the host specific DNA of clone 6, we assume that this DNA fragment of approximately $2 \mathrm{~kb}$ belongs to the unique sequence class within the mouse genome.

The observation that all EcoRI fragments of $\mathrm{C} 3 \mathrm{H}, \mathrm{BALB} / \mathrm{c}$, and GR DNA which could be recognized by MMTV cDNA were also identifiable by $B_{2}-E_{\mathrm{C} 6}$ allows a conclusion to be drawn about the terminal redundancies present at the ends of the proviral genes. If the end fragment $B_{2}-E_{C_{6}}$ contains sequences homologous to the $5^{\prime}$ and $3^{\prime}$ end of the viral RNA as has been described for the proviral sequences of avian sarcoma virus (9), then one would expect that all MMTV-specific EcoRI fragments of the endogenous proviral copies would be recognized. A notable exception is the feral mouse DNA. Two bands could be recognized by MMTV cDNA (Fig. 7C); however, only the upper of these two bands hybridized with $\mathrm{B}_{2}-\mathrm{E}_{\mathrm{C} 6}$. The second band observed in Fig. 7B (fifth lane) corresponds to the presumptive integration site fragment. The 


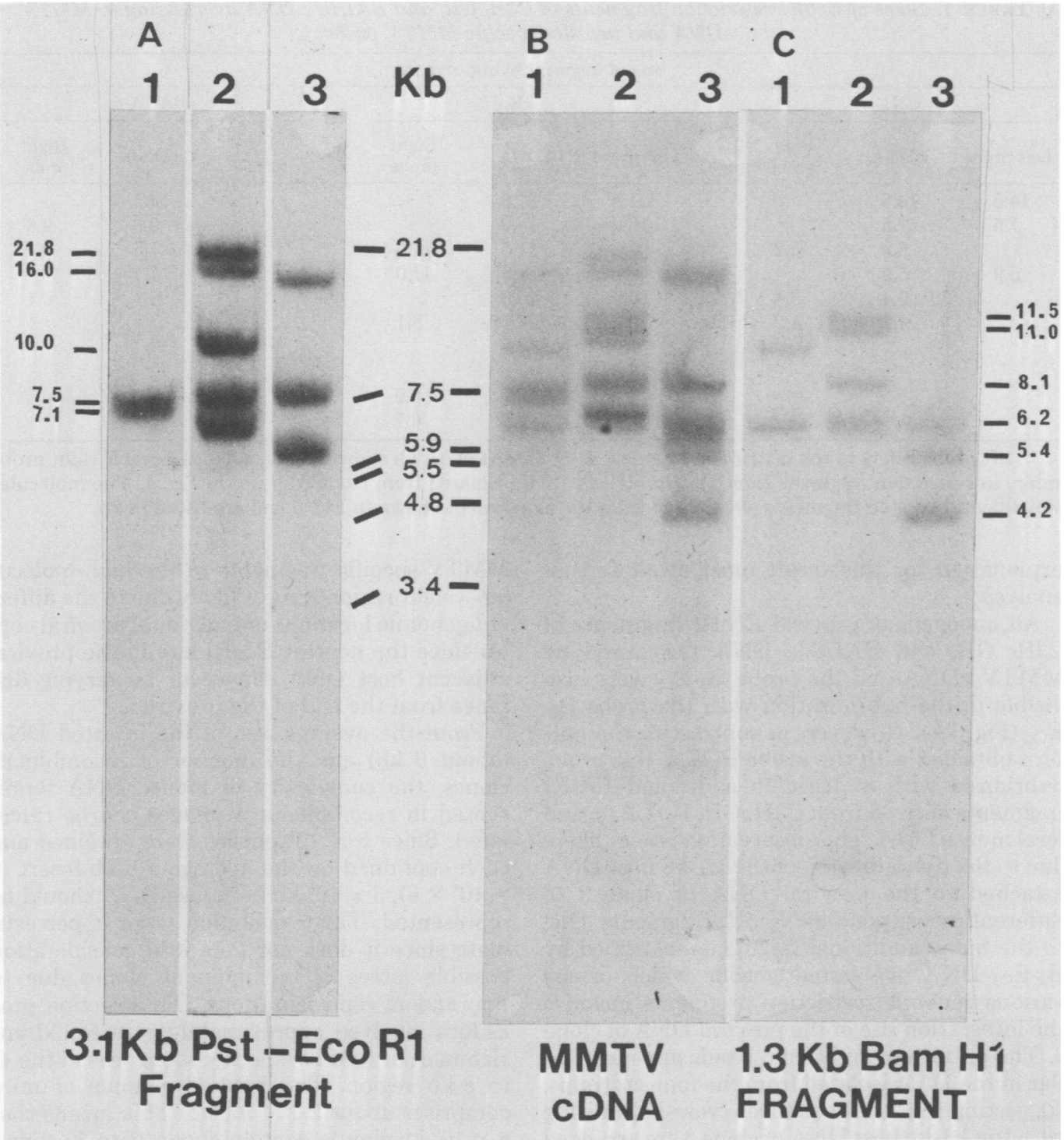

Fig. 6. Identification of MMTV-specific EcoRI restriction fragments of genomic DNA of C3H, GR, and $B A L B / c$ mice with molecular hybridization probes specific for the left $\left(5^{\prime}\right)$ and right (3') sides. (A) $20 \mu g$ of DNA from (lane 1) BALB/c, (lane 2) GR, and (lane 3) C3H livers was digested with EcoRI and transferred to a nitrocellulose filter after electrophoresis in a $0.8 \%$ agarose gel. The filter was hybridized with a 3.1-kb PstI/ EcoRI restriction fragment labeled in vitro, which represents nucleotide sequences specific for the left $\left(5^{\prime}\right)$ side of the provirus (schematically shown in Fig. 4). The isolation of this restriction fragment is described in Fig. 1. (B) (Lane 1) BALB/c, (lane 2) GR, and (lane 3) C3H liver DNA EcoRI fragments (as described in A) were hybridized to a representative $\left.{ }^{32} P\right] c D N A$ probe (6). (C) (Lane 1) BALB/c, (lane 2) GR, and (lane 3) C3H liver DNA EcoRI fragments (as described in A) were hybridized to the $B_{1}-B_{2}$ fragment of clone 3 (Fig. 4). This 1.3kb BamHI fragment was preparatively isolated after BamHI digestion of the EcoRI insert of clone 3 . It represents nucleotide sequences specific for the right (3') side of the proviral DNA. The molecular weights of the restriction fragments observed are listed in Table 1. To facilitate an analysis of these fragments, on the left and right sides of the figure we have indicated some of the EcoRI MMTV-specific fragments listed in Table 1. The markers in the center indicate the position of the fragments of EcoRI-cut lambda phage DNA. 
TABLE 1. Sizes of EcoRI restriction fragments of $C 3 H, G R$, and $B A L B / c D N A$ hybridizing to $M M T V$ cDNA and two site-specific MMTV probes

\begin{tabular}{|c|c|c|c|c|c|c|c|c|}
\hline \multicolumn{9}{|c|}{ Size of fragment hybridizing to ${ }^{a}$ : } \\
\hline \multicolumn{3}{|c|}{ C3H } & \multicolumn{3}{|c|}{ GR } & \multicolumn{3}{|c|}{ BALB/c } \\
\hline Left probe & cDNA & $\begin{array}{l}\text { Right } \\
\text { probe }\end{array}$ & Left probe & cDNA & $\begin{array}{l}\text { Right } \\
\text { probe }\end{array}$ & $\begin{array}{c}\text { Left } \\
\text { probe }\end{array}$ & cDNA & $\begin{array}{l}\text { Right } \\
\text { probe }\end{array}$ \\
\hline 14.5 & 14.5 & & 21.8 & 21.8 & & & 14.5 & \\
\hline \multirow[t]{2}{*}{7.5} & 7.5 & & 16.0 & 16.0 & & & 9.6 & 9.6 \\
\hline & 6.2 & 6.2 & & 11.5 & 11.5 & 7.5 & 7.5 & \\
\hline \multirow[t]{7}{*}{5.9} & 5.9 & & & 11.0 & 11.0 & 7.1 & 7.1 & \\
\hline & 5.4 & 5.4 & 10.0 & 10.0 & & & 6.1 & 6.1 \\
\hline & 4.2 & 4.2 & & 8.1 & 8.1 & & & \\
\hline & & & 7.8 & 7.8 & & & & \\
\hline & & & 7.0 & 7.0 & & & & \\
\hline & & & & 6.9 & 6.9 & & & \\
\hline & & & & 6.7 & 6.7 & & & \\
\hline
\end{tabular}

${ }^{a}$ Left probe refers to the restriction fragment PstI/EcoRI of $3.1 \mathrm{~kb}$ shown in Fig. 1, lanes 4 and 5 ; right probe refers to restriction fragment $B a m H_{1} / B a m H_{2}$ of $1.3 \mathrm{~kb}$ isolated from clone 3 shown in Fig. 4. The molecular weights of the listed fragments were taken from the experiment shown in Fig. 6 and are listed in kb.

explanation for this result must await further analysis.

All endogenous proviral EcoRI fragments of $\mathrm{C} 3 \mathrm{H}, \mathrm{GR}$, and BALB/c DNA recognized by MMTV cDNA and the probe $B_{2}-E_{C 6}$ were also visible in the hybridization with the probe $B_{2}$ $\mathrm{E}_{\mathrm{C} 3}$ (Fig. 7A). However, in contrast to the pattern obtained with the probe $\mathrm{B}_{2}-\mathrm{E}_{\mathrm{C} 6}$, this probe hybridized with at least 15 additional EcoRI fragments derived from $\mathrm{C} 3 \mathrm{H}, \mathrm{GR}, \mathrm{BALB} / \mathrm{c}$, and feral mouse DNA. This observation is very likely due to the hybridization of the 1.1-kb host DNA attached to the proviral DNA of clone 3 to different mouse genomic EcoRI fragments. Due to the many additional fragments identified by $B_{2}-E_{C 3}$ DNA, we cannot decide which of the various genomic restriction fragments includes the integration site of the proviral DNA of clone 3 . The pattern of additional bands appears similar in the DNA isolated from the mouse strains, suggesting that the sequences cross-hybridizing with the 1.1-kb host DNA of clone 3 are arranged similarly in the genomic DNA of these mice.

\section{DISCUSSION}

The DNA used for the construction of $\lambda$ recombinant clones was isolated from the 4- to 8$\mathrm{kb}$ region of an EcoRI digest of GR cell line DNA. No or very few MMTV-specific EcoRI fragments smaller than $4 \mathbf{k b}$ could be detected (Fig. 2). This is probably because exogenous viral DNA integrates into genomic DNA to yield a provirus which is colinear with viral RNA. Since the EcoRI site is located about $3.9 \mathrm{~kb}$ from the right-hand end of the provirus $(10,22)$, no MMTV-specific fragments smaller than that would be expected if all copies are integrated in a colinear fashion. The broad distribution of
MMTV-specific fragments in the high-molecular-weight region is most likely due to the different genomic locations of individual proviral copies since the nearest $E c o R I$ site in the proviral adjacent host DNA can occur at varying distance from the end of the provirus.

From the average size of the inserted DNA (about $6 \mathrm{~kb}$ ) and the number of recombinant clones, the complexity of mouse DNA represented in recombinant $\lambda$ phages can be calculated. Since $5 \times 10^{4}$ phages were obtained and each contained on the average a 6-kb insert (5 $\left.\times 10^{4} \times 6\right), 3 \times 10^{5} \mathrm{~kb}$ of mouse DNA should be represented. This calculation is an upper estimate since it does not take into consideration possible losses of recombinant clones due to nonrandom representations. Our selection procedure involved approximately a threefold enrichment of MMTV-specific sequences in the 4to 8-kb region. The haploid genome of mice comprises about $2.3 \times 10^{6} \mathrm{~kb}$. This means that $8 \times 10^{5} \mathrm{~kb}$ should contain about 25 to 30 copies of the proviral MMTV DNA. Since we cloned about $3 \times 10^{5} \mathrm{~kb}$, approximately one-third, i.e., 8 to 10 copies of the proviral DNA, should be included. Our finding of six right-hand fragments approaches this number. However, the corresponding left-hand fragments were also expected to be present. At this point it is not clear why none were isolated during the screening procedure. A possible explanation is that recombinant phages carrying these DNA sequences have a selective growth disadvantage. Since the cloning and screening procedure involves an amplification step of in vitro-packaged $\lambda$ phage, it is possible that at this stage left-hand proviral sequences form smaller plaques and elude the subsequent screening because of their underrep- 


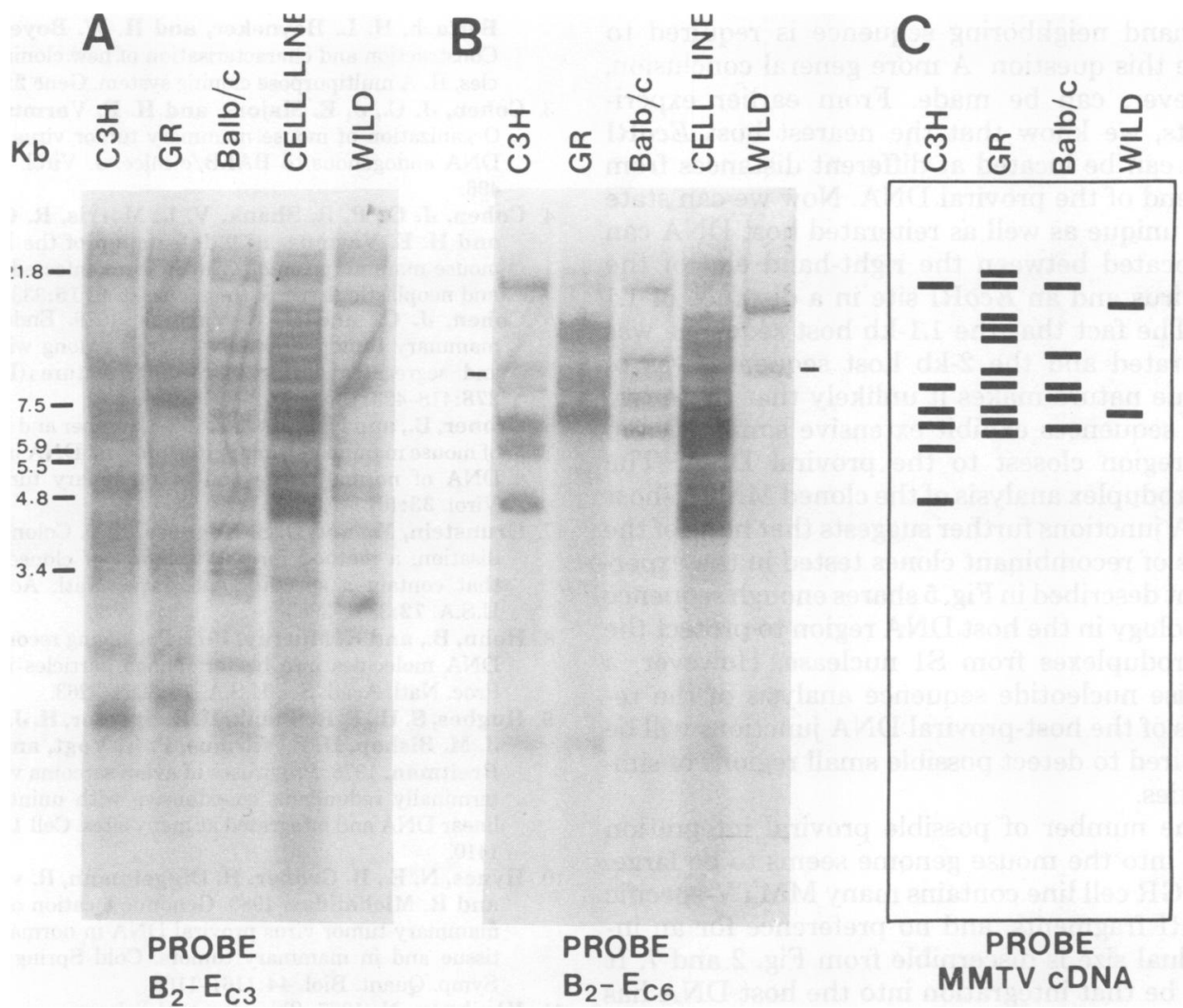

FIG. 7. Identification of EcoRI restriction fragments of different mouse strains which share sequence homology with the fragment $B_{2}-E_{\mathrm{C} 3}$ (fragment of clone 3 comprising the 3 -terminal sequences of the proviral $D N A$ and $1.1 \mathrm{~kb}$ of adjacent host DNA) and $B_{2}-E_{\mathrm{C}}$ (fragment of clone 6 comprising the same 3 -terminal proviral DNA and $1.1 \mathrm{~kb}$ of adjacent host DNA. (A) $20 \mu \mathrm{g}$ of (lane 1) C3H, (lane 2) GR, (lane 3) BALB/c, (lane 4) GR cell line, and (lane 5) feral mouse DNA was digested with EcoRI, electrophoresed in a 0.8\% agarose gel, and transferred to a nitrocellulose filter. The DNA was hybridized with the nick-translated probe $B_{2}-E_{\mathrm{C} 3}$ derived as described in Fig. 4. (B) $20 \mu \mathrm{g}$ of EcoRI fragments (as described in A) were hybridized with the nicktranslated probe $B_{2}-E_{\mathrm{C} 6}$ derived as described in Fig. 4. The bars to the left and right indicate the position of a hybridizing fragment which is not recognized by a representative $c D N A$ probe. $(C) S c h e m a t i c$ representation of EcoRI fragments of $C 3 H, G R, B A L B / c$, and feral mouse liver DNA which can be recognized by a representative $c D N A$ probe.

resentation. This explanation seems likely since we have recently obtained a recombinant clone from GR liver DNA which contains right- as well as left-hand EcoRI fragments of endogenous proviral DNA.

Our experiments demonstrate that a GR cell line host DNA sequence of approximately $2 \mathrm{~kb}$ which is immediately adjacent to the right-hand end of the proviral DNA of clone 6 belongs to the unique class of DNA in the mouse genome. This demonstration was possible because the site into which the proviral DNA in the cell line was integrated was "empty" in the DNA of the other mice strains tested. The 2-kb host DNA contained in probe $B_{2}-E_{C 6}$ hybridized to a 8.3-kb $E c o R I$ restriction fragment present in all tested mice strains. $\mathrm{By}$ using this $\mathrm{B}_{2}-\mathrm{E}_{\mathrm{C} 6}$ probe, it will be possible to isolate and amplify this $8.3-\mathrm{kb}$ fragment. This isolation and characterization of the integration site in clone 6 and in the corresponding status quo ante in the 8.3-kb fragment could yield some insight into the mechanism of the integration event (11).

The multiple number of restriction fragments recognized by the 1.1-kb DNA immediately adjacent to clone 3 proviral DNA indicates that proviral integration in the GR cell line can occur adjacent to unique sequence DNA as well as to reiterated host sequences. The reiterated sequence must be contained within the $1.1 \mathrm{~kb}$ to the right of the proviral DNA of clone 3. This does not allow us to decide whether this provirus was integrated directly into a reiterated DNA sequence or adjacent to it. The isolation of the 
left-hand neighboring sequence is required to solve this question. A more general conclusion, however, can be made. From earlier experiments, we know that the nearest host EcoRI sites can be located at different distances from the end of the proviral DNA. Now we can state that unique as well as reiterated host DNA can be located between the right-hand end of the provirus and an EcoRI site in a distance of 1.1 $\mathrm{kb}$. The fact that the 1.1-kb host sequence was reiterated and the 2-kb host sequence was of unique nature makes it unlikely that these two host sequences exhibit extensive similarities in the region closest to the proviral DNA. The heteroduplex analysis of the cloned MMTV-host DNA junctions further suggests that none of the pairs of recombinant clones tested in the experiment described in Fig. 5 shares enough sequence homology in the host DNA region to protect the heteroduplexes from S1 nuclease. However, a precise nucleotide sequence analysis of the regions of the host-proviral DNA junctions will be required to detect possible small regions of similarities.

The number of possible proviral integration sites into the mouse genome seems to be large. The GR cell line contains many MMTV-specific $E c o R I$ fragments, and no preference for an individual size is discernible from Fig. 2 and 7. It may be that integration into the host DNA has no or only or very slight sequence specificity. Then at which level is the control exerted over proviral gene expression? One possibility is that the initial integration event locates the incoming provirus in transcribed as well as nontranscribed DNA. This difference in transcriptional activity could be based, for example, on DNA modifications or upon its tertiary structure. The provirus might carry all the necessary signals for its expression which function only if the proviral DNA reaches a proper environment.

\section{ACKNOWLEDGMENTS}

We thank S. Jeep for excellent technical assistance, $P$. Leder for the $\lambda$ gt WES. $\lambda B$ cloning kit, B. Hohn for help with the in vitro packaging of $\lambda$ phages, $J$. Beard for avian myeloblastosis virus reverse transcriptase, and $G$. Kammerer and $C$. Heinold for the preparation of the manuscript.

This work was supported by grants 3.706-0.76 SR and 3.2730.78 SR from the Swiss National Science Foundation. N.E.H. was supported in part by a grant from the Swiss Cancer League.

\section{LTERATURE CITED}

1. Benton, W. D., and R. W. Davis. 1977. Screening $\lambda$ gt recombinant clones by hybridisation to single plaques in situ. Science 186:180-182.

1a.Bentvelven, P., and J. Hilgers. 1980. The murine mammary tumor virus, p. 311-355. In G. Klein (ed.), Viral oncology. Raven Press, New York.

2. Bolivar, F., R. L. Rodriguez, P. J. Greene, M. C.
Bettach, H. L. Heyneker, and H. W. Boyer. 1977. Construction and characterisation of new cloning vehicles. II. A multipurpose cloning system. Gene 2:95-113.

3. Cohen, J. C., J. E. Majors, and H. E. Varmus. 1979. Organization of mouse mammary tumor virus specific DNA endogenous to BALB/c mice. J. Virol. 32:483496.

4. Cohen, J. C., P. R. Shank, V. L. Morris, R. Cardiff, and H. E. Varmus. 1979. Integration of the DNA of mouse mammary tumor virus in virus infected normal and neoplastic tissue of the mouse. Cell 16:333-345.

5. Cohen, J. C., and H. E. Varmus. 1979. Endogenous mammary tumor virus DNA varies among wild mice and segregates during inbreeding. Nature (London) 278:418-423.

6. Groner, B., and N. E. Hynes. 1980. Number and location of mouse mammary tumor virus proviral DNA in mouse DNA of normal tissue and of mammary tumors. J. Virol. 33:1013-1025.

7. Grunstein, M., and D. S. Hogness. 1975. Colony hybridisation: a method for the isolation of cloned DNAs that contain a specific gene. Proc. Natl. Acad. Sci. U.S.A. 72:3961-3965.

8. Hohn, B., and K. Murray. 1977. Packaging recombinant DNA molecules into bacteriophage particles in vitro. Proc. Natl. Acad. Sci. U.S.A. 74:3259-3263.

9. Hughes, S. H., P. R. Shank, D. H. Spector, H. J. Kung, J. M. Bishop, H. E. Varmus, P. K. Vogt, and M. L. Breitman. 1978. Proviruses of avian sarcoma virus are terminally redundant, co-extensive with unintegrated linear DNA and integrated at many sites. Cell 15:13271410.

10. Hynes, N. E., B. Groner, H. Diggelmann, R. van Nie, and $R$. Michalides. 1980. Genomic location of mouse mammary tumor virus proviral DNA in normal mouse tissue and in mammary tumors. Cold Spring Harbor Symp. Quant. Biol. 44:1161-1168.

11. Kleckner, N. 1977. Translocatable elements in procaryotes. Cell 11:11-23.

12. Leder, P., D. Tiemeier, and L. Enquist. 1977. EK2 derivatives of bacteriophage $\lambda$ useful in the cloning of DNA from higher organisms: the $\lambda g t$ WES system. Science 196:175-177.

13. Leder, P., D. C. Tiemeier, S. M. Tilghman, and L. W. Enquist. The $\lambda g t$ WES $\lambda$ B cloning system. Owners manual.

14. Maniatis, T., R. C. Hardison, E. Lacy, J. Laner, C. O'Connell, D. Quon, G. K. Sim, and A. Efetratiadis. 1978. The isolation of structural genes from libraries of eukaryotic DNA. Cell 15:687-70i.

15. Michalides, R., G. Vlahakis, and J. Schlom. 1976. A biochemical approach to the study of the transmission of mouse MTV in mouse strain RIII and C3H. Int. J. Cancer 18:105-115.

16. Morris, V. L., E. Medeiros, G. M. Ringold, M. J. Bishop, and H. E. Varmus. 1977. Comparison of mouse mammary tumor virus specific DNA in inbred, wild and Asian mice, and in tumors and normal organs from inbred mice. J. Mol. Biol. 114:73-91

17. Ringold, G. M. 1979. Glucocorticoid regulation of mouse mammary tumor virus gene expression. Biochim. Biophys. Acta 560:487-508.

18. Ringold, G. M., R. D. Cardiff, H. E. Varmus, and K. R. Yamamoto. 1977. Infection of cultured rat hepatoma cells by mouse mammary tumor virus. Cell 10:1118.

19. Ringold, G. M., E. K. Lasfargues, J. M. Bishop, and H. E. Varmus. 1975. Production of mouse mammary tumor virus by cultured cells in the absence and presence of hormones: assay by molecular hybridisation. Virology 65:135-147.

20. Ringold, G. M., P. R. Shank, H. E. Varmus, J. Ring, 
and K. R. Yamamoto. 1979. Integration and transcription of mouse mammary tumor virus DNA in rat hepatoma cells. Proc. Natl. Acad. Sci. U.S.A. 76:665-669.

21. Saint, R. B., and J. B. Egan. 1979. A method which facilitates the ordering of DNA restriction fragments. Mol. Gen. Genet. 171:103-106.

22. Shank, P. R., J. C. Cohen, H. E. Varmus, K. R. Yamamoto, and G. M. Ringold. 1978. Mapping of linear and circular forms of mouse mammary tumor virus DNA with restriction endonucleases: evidence for a large specific deletion occurring at high frequency during circularisation. Proc. Natl. Acad. Sci. U.S.A. 75: 2112-2116.

23. Southern, E. M. 1975. Detection of specific sequences among DNA fragments separated by gel electrophore- sis. J. Mol. Biol. 98:503-517.

24. Vaidya, A. B., E. Y. Lasfargues, G. Heubel, J. C. Lasfargues, and D. H. Moore. 1976. Murine mammary tumor virus: characterization of infection of nonmurine cells. J. Virol. 18:911-917.

25. Varmus, H. E., G. M. Ringold, and K. R. Yamamoto. 1979. Regulation of mammary tumor virus gene expression by glucocorticoid hormones, p. 253-278. In J. D. Baxter and G. G. Rousseau (ed.), Glucocorticoid hormone action. Springer Verlag. New York.

26. Young, H. A., T. Y. Shih, E. M. Scolnick, and W. P. Parks. 1977. Steroid induction of mouse mammary tumor virus: effect upon synthesis and degradation of viral RNA. J. Virol. 21:139-146. 